\title{
JOHANN MAIER
}

STUDIEN ZUR JÜDISCHEN BIBEL UND IHRER GESCHICHTE

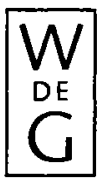




\title{
STUDIA JUDAICA
}

FORSCHUNGEN ZUR WISSENSCHAFT DES JUDENTUMS

\author{
HERAUSGEGEBEN VON \\ E. L. EHRLICH UND G. STEMBERGER
}

BAND XXVIII

WALTER DE GRUYTER - BERLIN · NEW YORK 


\title{
STUDIEN ZUR JÜDISCHEN BIBEL UND IHRER GESCHICHTE
}

\author{
VON \\ JOHANN MAIER
}

WALTER DE GRUYTER - BERLIN - NEW YORK 
(O) Gedruckt auf säurefreiem Papier, das die US-ANSI-Norm über Haltbarkeit erfüllt.

ISBN 3-11-018209-2

\section{Bibliografische Information Der Deutschen Bibliothek}

Die Deutsche Bibliothek verzeichnet diese Publikation in der Deutschen Nationalbibliografie; detaillierte bibliografische Daten sind im Internet über http://dnb.ddb.de abrufbar.

(C) Copyright 2004 by Walter de Gruyter GmbH \& Co. KG, D-10785 Berlin.

Dieses Werk einschließlich aller seiner Teile ist urheberrechtlich geschützt. Jede Verwertung außerhalb der engen Grenzen des Urheberrechtsgesetzes ist ohne Zustimmung des Verlages unzulässig und strafbar. Das gilt insbesondere für Vervielfältigungen, Übersetzungen, Mikroverfilmungen und die Einspeicherung und Verarbeitung in elektronischen Systemen.

\section{Printed in Germany} Einbandgestaltung: Christopher Schneider, Berlin 